\title{
Augmented reality application for location finder guidance
}

\author{
Anatun Nadrah Rosman, Noor Azah Samsudin, Azizan Ismail, Muhammad Syariff Aripin, \\ Shamsul Kamal Ahmad Khalid \\ Faculty of Computer Science and Information Technology, Universiti Tun Hussein Onn Malaysia, \\ Johor, Malaysia
}

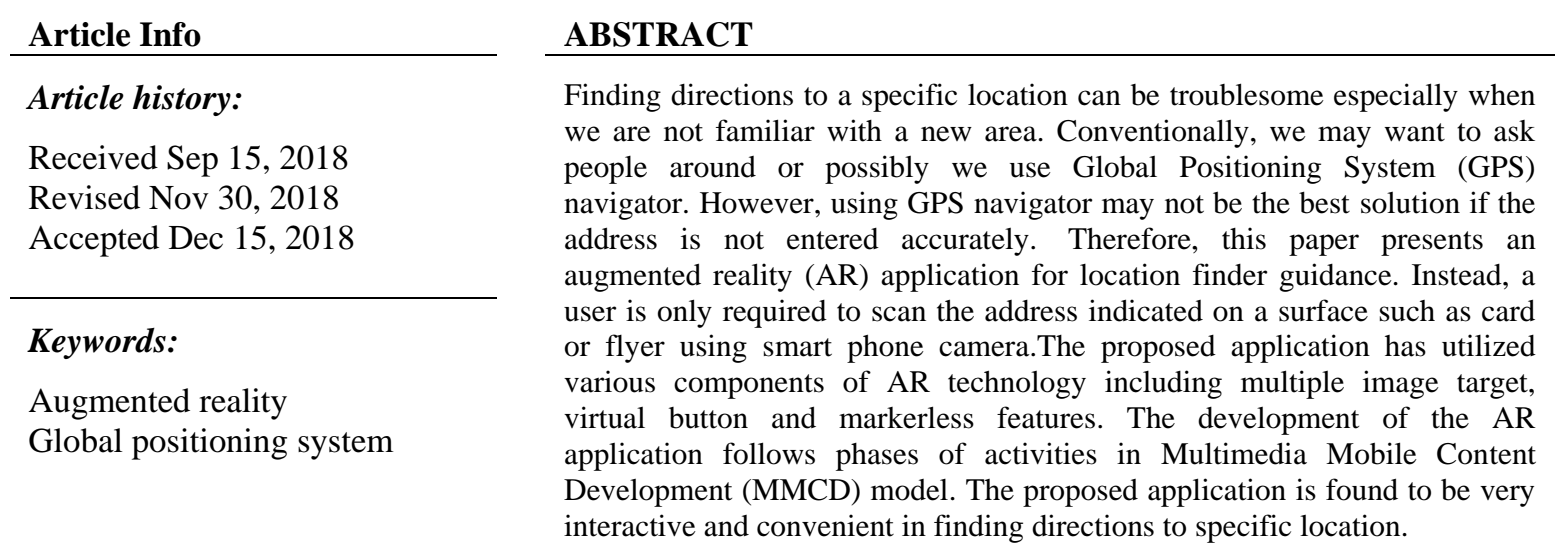

\section{Corresponding Author:}

Noor Azah Samsudin,

Faculty of Computer Science and Information Technology,

Universiti Tun Hussein Onn Malaysia,

86400 Batu Pahat, Johor, Malaysia.

Email: azah@uthm.edu.my

\section{INTRODUCTION}

Augmented reality (AR) is a new technology that enables mixing of real environment and virtual objects created in a 3D environment with interactive functions [1]-[3]. In AR application, some of the elements in real-world environment are augmented by computer-generated sensory input such as sound, video, graphics or Global Positioning System (GPS) data [2]. Different from virtual reality application which demonstrates totally artificial environment, AR application is closer to real-world environment [4]. AR technology has been applied in various applications including education, e-commerce, business, automobile, and tourism [5]-[10]. The existing AR applications are known for their benefits of more interactive delivery, closer proximity to real-world environment and attractive information display.

Our interest in this study, is to explore the potential of AR technology in finding specific destination, given an address on an invitation card, business card, and flyers. One of the many problems while travelling to unfamiliar addresses, is one may find difficulties to find directions to the specific destination. Possible solutions may include asking people around to query for directions or using GPS navigator. However, both solutions are prone to some limitations. The information given by humans may not be sufficient, while typing the address or coordinate manually on the GPS navigator may be inaccurate [11],[12]. The capability of AR technology in utilizing features such as markerless GPS coordinates utilities, multiple image target, virtual buttons, 2D and 3D modelling [13], [14] shall be explored to solve the limitations in finding the desired destination or location. 
This paper presents an augmented reality application for location finder guidance. In this study, we will present main activities in the phases of the ARGUIDE development in Section 2. Next, Section 3 will explain implementation and testing of the proposed ARGUIDE. Finally, Section 4 presents some conclusions of the ARGUIDE development work.

\section{RESEARCH METHOD}

The ARGUIDE is proposed with the aim to find location of the address indicated in business card, invitation card, or flyers. A user has to scan specific image target, that is the address to view the 3D object, virtual button and information. Then the user can touch the virtual button, and eventually the application will send GPS coordinate that connect to Google Map, Waze or other maps application. Interestingly, users can also view information about the location presented in image and textual form. To encourage usability, the ARGUIDE is proposed to operate on android platform for potential users.

The ARGUIDE was developed according to the phases in Multimedia Mobile Content Development (MMCD) [15]. Figure 1 shows five main phases of MMCD: application idea creation, structure analysis, process design, main function development, and testing.

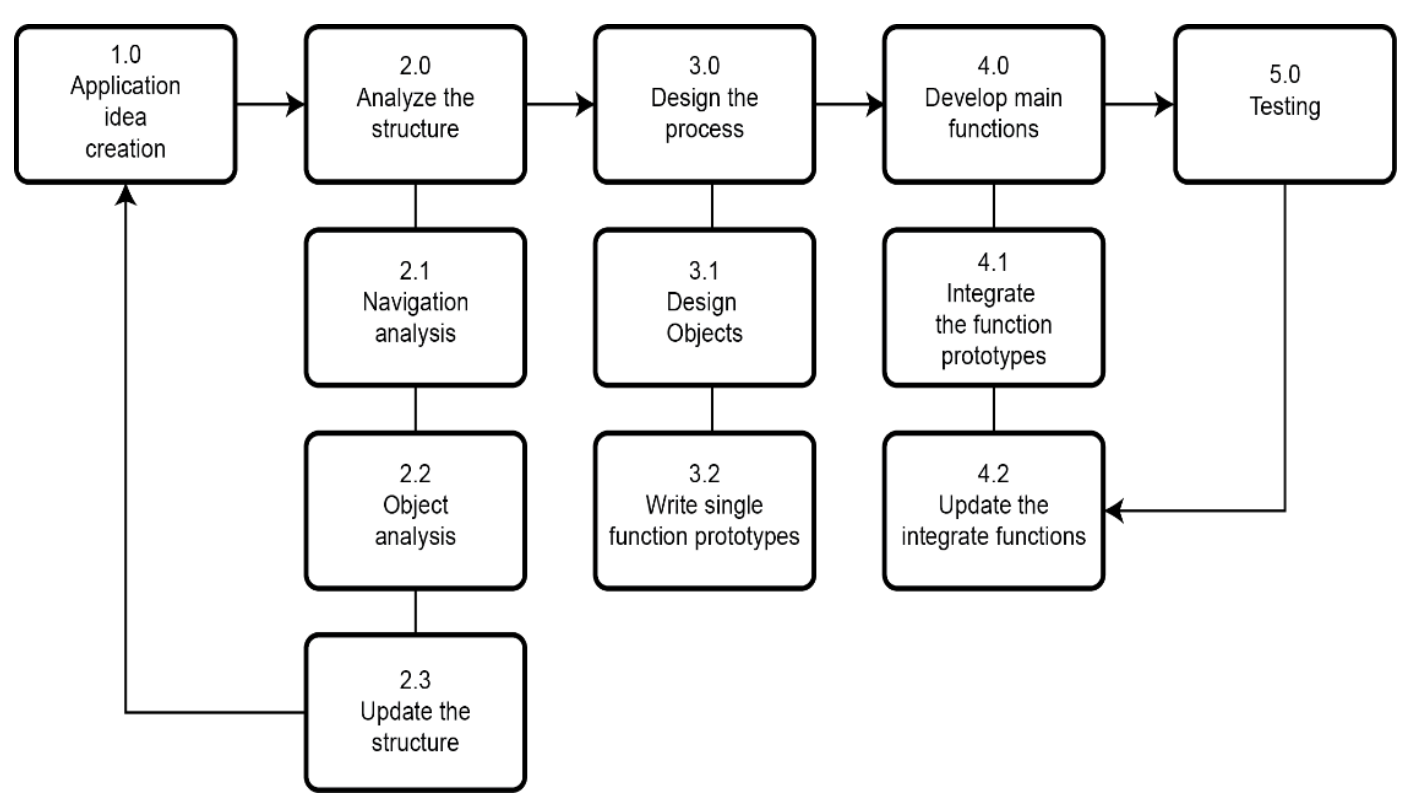

Figure 1. Phases of Multimedia Mobile Content Development (MMCD)

At the beginning of the development phase, the idea creation was focused on defining the design concept for business commercialization and tourism. The design concept of business commercialization and tourism was chosen as the design concept because the case studies to evaluate the proposed ARGUIDE involved two destinations: EZCetak and Tanjung Piai Johore National Park. The EZCetak is an event management company, while Tanjung Piai National Park is a recreational destination in Johore. For the EZCetak, the address is given on a business card. On the other hand, the address of the Tanjung Piai Johore National Park, the address is given on a flyer.

In the structure analysis phase, the objects and navigation structure for the ARGUIDE were then identified. The presentation of the application is narrated in story boards to confirm the flow of the application and target coordinates of destination. Then, in the process design phase, most activities focus on producing the ARGUIDE interface, virtual buttons, and background. The 3D model for selected objects were created, target images were designed, and a prototype was developed. A number of softwares were utilized in this phase, including 3D Unity, Blender, and Vuforia. An example of a 3D model with virtual objects and buttons in the ARGUIDE is shown in Figure 2. Next, in the main function development phase, a number of integration activities were carried out to ensure all of the application components, such as menu, submenu, modules, virtual buttons, and objects were functioning in a 3D setting. Finally, in the testing phase, a number of questionnaires were released to potential users of the ARGUIDE for preliminary feedback. 


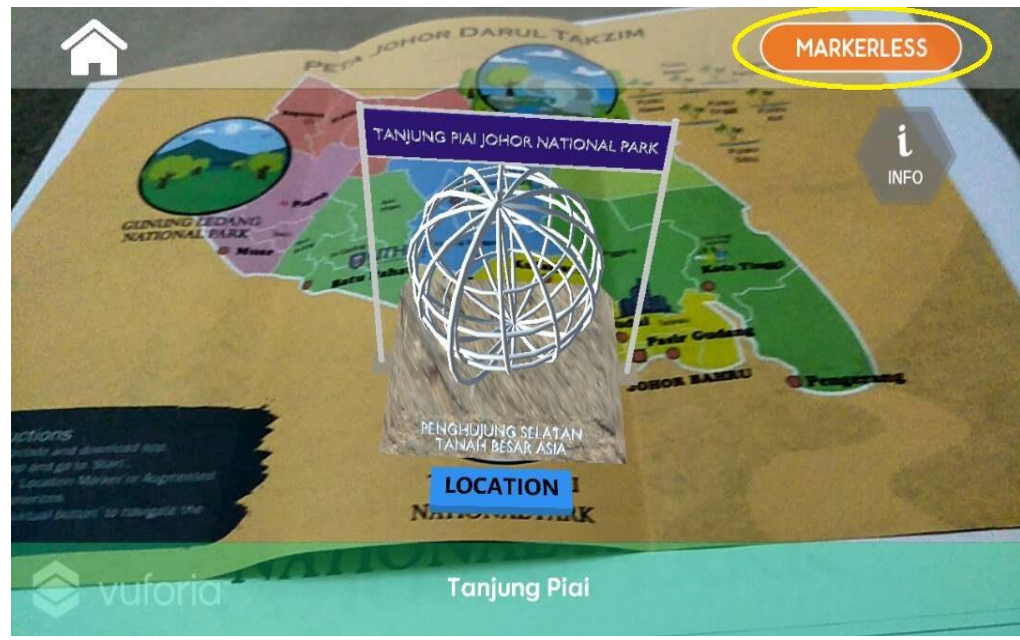

Figure 2. A 3D model with virtual button and objects in the ARGUIDE

\section{IMPLEMENTATION AND TESTING}

The interface for ARGUIDE was designed according to the business commercialization and tourism industry concept. In the case of Tanjung Piai Johore National Park, the entrance interface design is illustrated in Figure 3. The entrance interface design contains welcome message, coordinates information, and background of images of the destination. A user can scan specific image target to view the 3D object, virtual button and information. This application provides information displayed in textual and image forms. The direction to a specific location will be displayed when a user touches the virtual button. The input is sent, and the application will send GPS coordinate that connected to maps application. Eventually a navigated direction to the specific location or destination will be displayed. To encourage interactivity, the interface of ARGUIDE is also equipped with main menu, settings, help, about and AR scene.

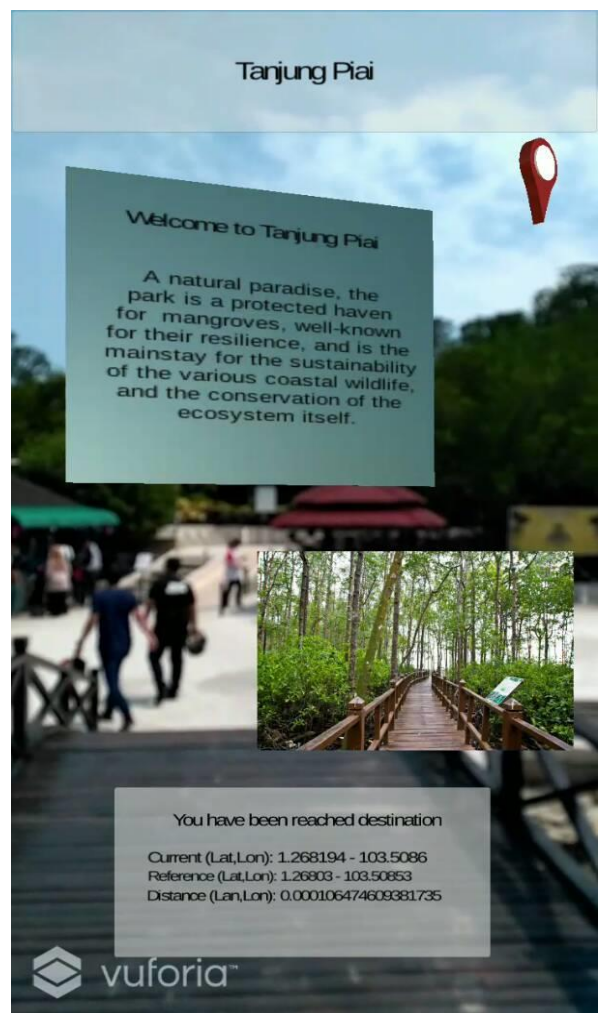

Figure 3. Interface design for the entrance to Tanjung Piai Johore National Park 
Main activities of the ARGUIDE implementation include environment preparation and coding of interaction modules. Unity 3D is used to create the environment of AR. The Unity 3D is helpful to facilitate interaction with the Vuforia database for the image target. The image target was designed using Adobe Illustrator CS6. Then, the image target can be uploaded to Vuforia website to make it as a database for the ARGUIDE. Figure 4 shows Vuforia website with a list of the databases that have been created. Figure 5 shows the image target interface with the features of the points in the image.

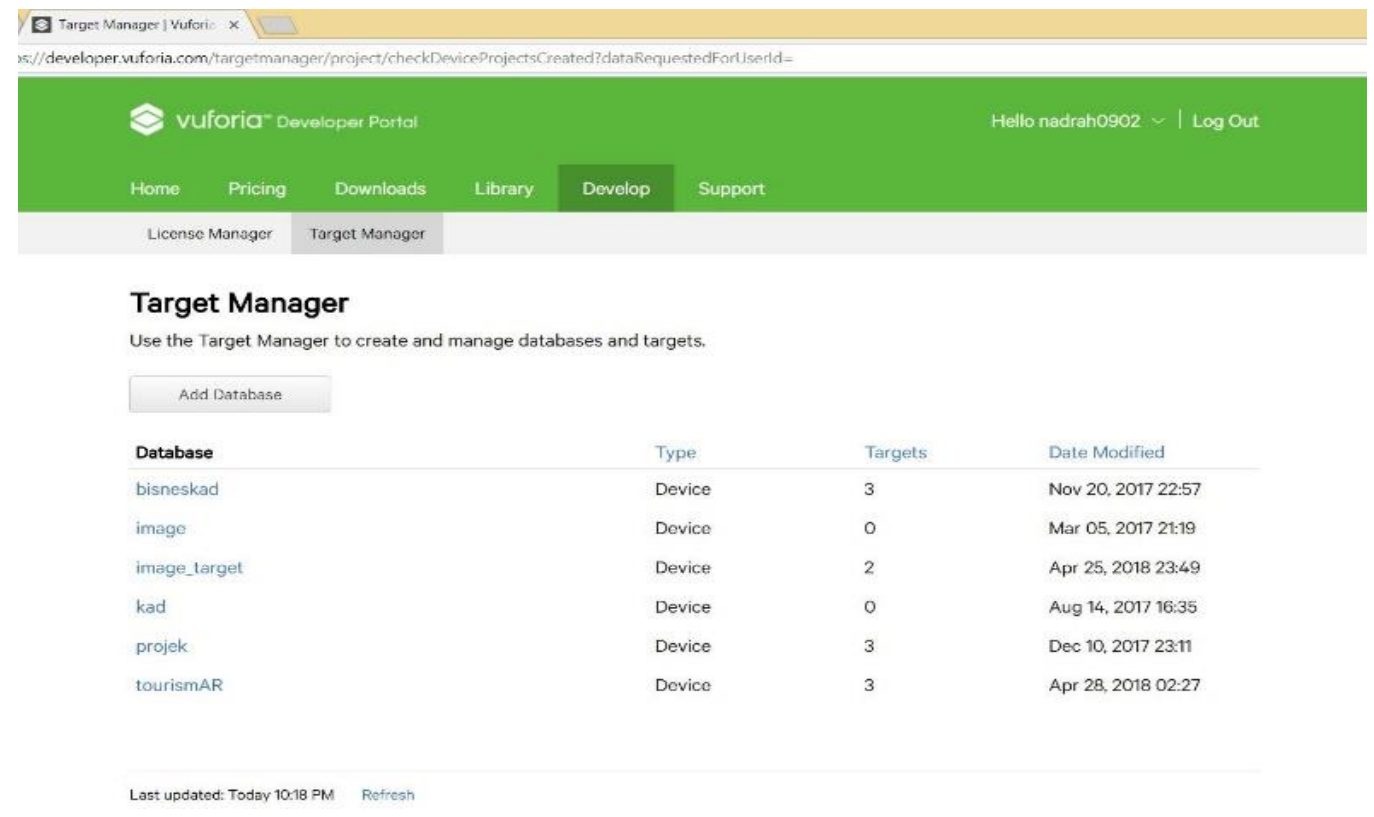

Figure 4. Vuforia website

tanjungpiai

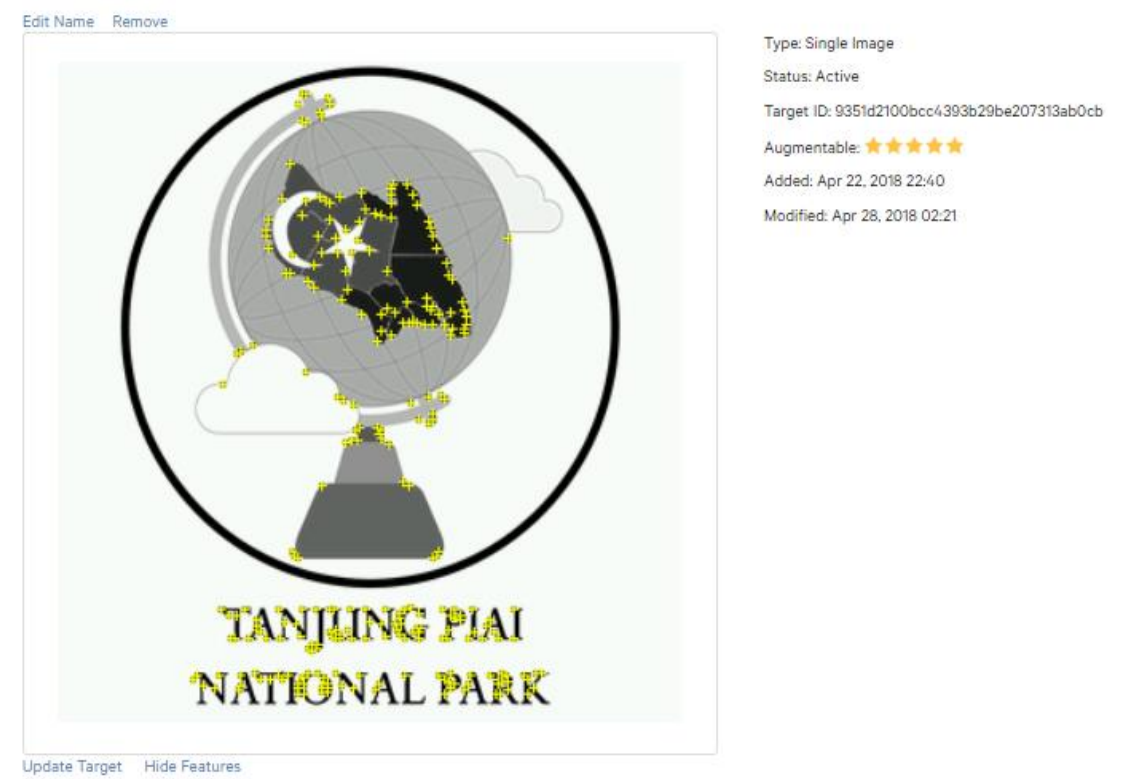

Figure 5. Image target

Figure 6 shows code segment for the image target. The code includes the target name, the information and some $3 \mathrm{D}$ objects and other objects too. 


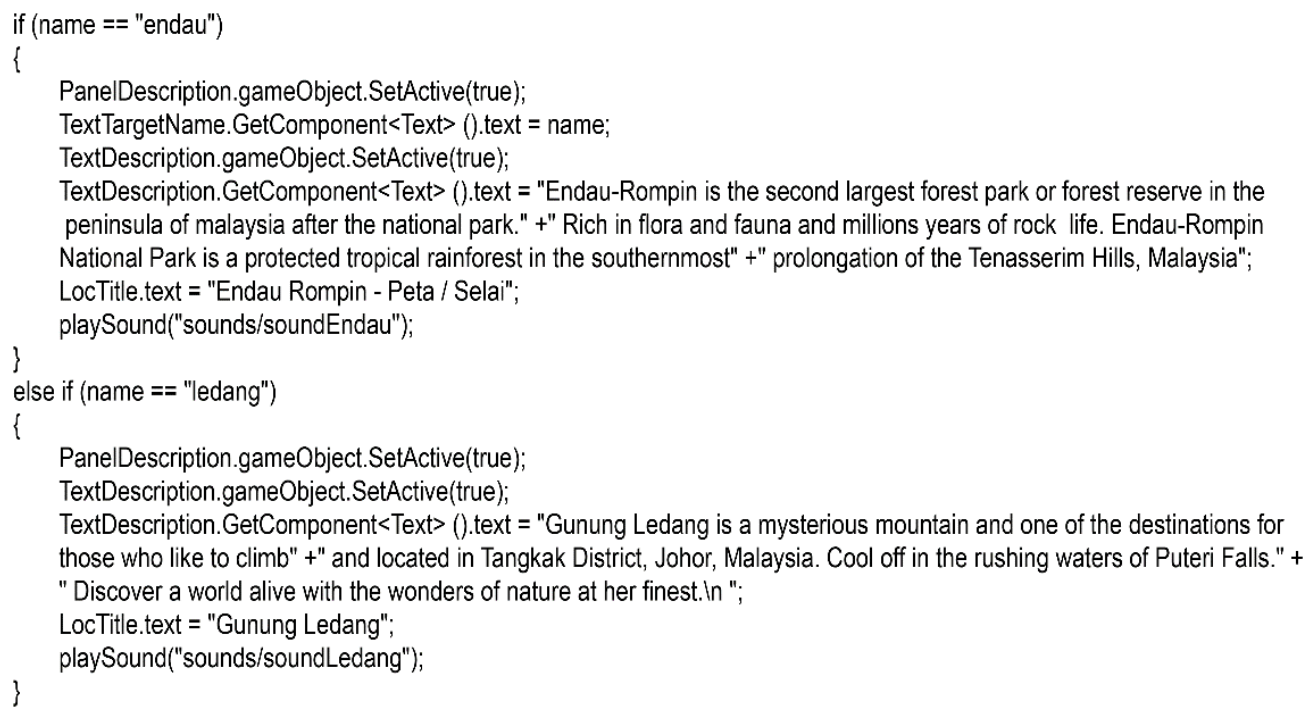

Figure 6. Code segment for image target

Preliminary testing with potential users have been carried out with staff of EZCetak and visitors of Tanjung Piai Johore National Park. More than $90 \%$ of the respondents agree that the ARGUIDE contains very clear instructions, friendly interface and easy to use to find directions. Indeed, majority of the respondents agree that the augmented reality based application will present a value added service for tourism industry. In addition, the EZCetak staff note the potential of the ARGUIDE in improving their value added service to customers in producing AR based business cards and invitation cards for its event management business.

\section{CONCLUSION}

This paper has presented an AR application for location finder guidance, called ARGUIDE. The ARGUIDE includes multiple interactive components that help potential users to find and navigate direction to desired destination. The ARGUIDE application has been evaluated with potential users in both organizations: EZCetak and Johor National Park. The preliminary testing shows that such AR based applications have the potential to provide alternative approach in finding specific locations using address images. In fact, such AR based application has been proven to improve business services in event management and tourism industries.

\section{ACKNOWLEDGEMENT}

This study is supported by a research grant under Ministry of Higher Education, Malaysia, Fundamental Research Grant Scheme Vot 1609 and partly sponsored by Gates IT Solution Sdn. Bhd.

\section{REFERENCES}

[1] Barfield, W "Fundamentals of Wearable Computers and Augmented Reality," Florida, CRC Press Taylor \& Francis Group, 2015.

[2] Nóbrega, R, Jacob, J., Coelho, A., Weber, J., Ribeiro, J., \& Ferreira, S. "Mobile location-based augmented reality applications for urban tourism storytelling," Computação Gráfica e Interação (EPCGI), $201724^{\circ}$ Encontro Português de, pp. 1-8, 2017.

[3] Tanaka, M., Misra, A., Oshima, K., Hashiguchi, S., Mori, S., Shibata, F., \& Tamura, H, "Further Experiments and Considerations on Weight Perception Caused by Visual Diminishing of Real Objects," Mixed and Augmented Reality (ISMAR-Adjunct), 2017 IEEE International Symposium on, pp. 160-161, 2017.

[4] Wei, X., Weng, D., Liu, Y., \& Wang, Y., "A tour guiding system of historical relics based on augmented reality," Virtual Reality (VR), 2016 IEEE, pp. 307-308, 2016.

[5] Montero, A., Zarraonandia, T., Diaz, P., \& Aedo, I, "Designing and implementing interactive and realistic augmented reality experiences," Universal Access in the Information Society, pp. 1-13, 2017.

[6] Zhang, B. "Design of mobile augmented reality game based on image recognition," EURASIP Journal on Image and Video Processing, 2017. 
[7] Aukstakalnis, S. "Practical Augmented Reality,” United State, Mark L.Taub., 2016.

[8] Peddie, Jon. "Augmented Reality: Where We Will All Live," United State, Springer Nature, 2017.

[9] Burns, M. "Deeper Learning with QR Codes and Augmented Reality: A Scannable Solution for Your Classroom (Corwin Teaching Essentials)," California, SAGE Publication LTD, 2016.

[10] Lanham, M. “Augmented Reality Game Development,” Birmingham, Packt Publishing LTD, 2017.

[11] Nuzzolese, E., Alqahtani, S. J., Adserias, J., \& Di Vella, G., "The Strengths and Weaknesses of Missing Persons Apps for Smartphones: A Forensic Expert’s Perspective," 69th Annual Scientific Meeting, pp. 917-917, 2017.

[12] Yovcheva, Z., Buhalis, D., \& Gatzidis, C., "Smartphone augmented reality applications for tourism," E-review of tourism research (ertr), vol/issue: 10(2), pp. 63-66, 2012.

[13] Liou, H. H., Yang, S. J., Chen, S. Y., \& Tarng, W. "The Influences of the 2D Image-Based Augmented Reality and Virtual Reality on Student Learning," Journal of Educational Technology \& Society, vol/issue: 20(3), 2017.

[14] Han, D. I., Jung, T., Gibson, A. (2013). Dublin AR: Implementing augmented reality in tourism. In Information and Communication Technologies in tourism. pp 511-523, Springer.

[15] W. S. N. S. Saifudin, S. Salam, and M. H. L. Abdullah, "Multimedia Mobile Content Development Framework and Methodology for Developing M-Learning Applications," Journal of Technical Education and Training, vol/issue: 4(1), pp. 15-21, 2012. 